\title{
Editorial for the Special Issue on Negative Appraisals in Trauma: Current Status and Future Directions for Research
}

\author{
Marcella L. Woud ${ }^{1}$ (1) Birgit Kleim² ${ }^{2}$ Jan C. Cwik ${ }^{3}$
}

Published online: 3 January 2019

(c) Springer Science+Business Media, LLC, part of Springer Nature 2019

\begin{abstract}
'Things will never be good again.' ... 'My reactions to the trauma show that there is something wrong with me.' ... 'Nobody and nothing can be trusted.' These are only some examples of idiosyncratic appraisals endorsed by survivors of traumatic events such as serious car accidents, natural disasters, or assaults. Within cognitive models of Posttraumatic Stress Disorder (PTSD) (e.g., Brewin et al. 1996; Ehlers and Clark 2000; Foa et al. 1989; Resick and Schnicke 1992), such negative appraisals are assumed to play a central role in how PTSD is developed and maintained. Negative appraisals, besides other factors, may thus explain why only a certain proportion of trauma survivors develop PTSD. More specifically, negative appraisals may lead to dysfunctional processing of and rumination about specific worst moments during the trauma, and may hamper the elaboration of trauma memories, leading in turn to posttraumatic stress symptoms such as intrusive memories of the trauma. These processes may then culminate in a vicious cycle of reinforced dysfunctional, trauma-related appraisal strategies and behaviors, such as avoidance.
\end{abstract}

A substantial body of evidence supports the role of negative appraisals in the development and maintenance of PTSD. To illustrate, there is an association between the extent to which people experience negative appraisals and the severity of their PTSD symptoms (e.g., Ehring et al. 2008; Kleim et al. 2013; Ter Heide et al. 2017), and their likelihood of meeting criteria for a diagnosis of PTSD

Marcella L. Woud

marcella.woud@rub.de

1 Department of Psychology, Mental Health Research and Treatment Center, Ruhr Universität Bochum, Massenbergstrasse 9-13, 44787 Bochum, Germany

2 Department of Psychiatry, Psychotherapy and Psychosomatics, University Hospital of Psychiatry Zürich, Lenggstrasse 31, 8032 Zurich, Switzerland

3 Department of Clinical Psychology and Psychotherapy, Faculty of Human Sciences, Universität zu Köln, Pohligstr. 1, 50969 Cologne, Germany (e.g., Dunmore et al. 1999; Jelinek et al. 2013). Further, in prospective studies it has been found that individuals who engage more in negative appraisals before experiencing a traumatic event subsequently experience higher levels of PTSD symptoms (e.g., Bryant and Guthrie 2005, 2007). Similarly, other studies have found that the degree to which individuals experience negative appraisals soon after they have experienced a trauma can predict how severe their PTSD symptoms are months later, including when controlling for initial symptom severity (e.g., Ehring et al. 2008; Kleim et al. 2007, and for a meta-analysis on predictors for PTSD, see; Ozer et al. 2003). Further, Kleim et al. (2013) examined the associations between dysfunctional appraisals and symptoms over the course of trauma-focused CBT. While reductions in dysfunctional appraisals predicted symptom reduction, the converse relationship was not found. Finally, an increasing amount of evidence supports the idea of a potential causal role for negative appraisals. For example, Woud et al. examined the effects of positive versus negative appraisal training on responses to trauma analogues such as distressing autobiographical events or film clips (Woud et al. 2012, 2013, 2018). Across these studies, results showed that participants in the positively-trained group, compared to those in the negatively-trained group, showed reduced levels of analogue posttraumatic stress symptoms, for example intrusion frequency or intrusion distress (for a review on assessing and manipulating biased cognitive processes in PTSD, see Vasterling and Hall 2018; Woud et al. 2017).

While theory and research have long pointed towards the important role for negative appraisals in PTSD, it was only with the fifth edition of the Diagnostic and Statistical Manual of mental disorders (DSM-5; American Psychiatric Association 2013) that this was also introduced as a core feature of PTSD and defined a diagnostic criterion (criterion D: negative alterations in cognitions and mood). Importantly, this cluster contains the greatest number of symptoms, specifically seven symptoms in total such as persistent negative 
expectations. Further, at least two of these symptoms need to be fulfilled in order to diagnose PTSD. In light of these developments and the clinical-diagnostic recognition of the importance of negative appraisals, the time now appears ripe for a fresh look at new developments in research on negative appraisals. This special issue therefore includes papers representing state-of-the-art studies that collectively illustrate the diversity of research on negative appraisals from various perspectives. The unique combination of papers in this special issue goes beyond previous research on negative appraisals. First, it contains papers examining the role of negative appraisals not only as a correlate of posttraumatic stress symptoms, but also as a predictor, and as a potential causal risk factor. According to Kraemer (1997), such a systematic and structured approach is needed when testing whether any particular factor can indeed be considered a causal risk factor. Applying this stepwise approach in the context of negative appraisals is crucial, particularly from a theoretical perspective, since many cognitive models of PTSD postulate that negative appraisals lead to or maintain posttraumatic stress symptoms. Second, the studies presented as part of this special issue did not examine PTSD and negative appraisals in isolation. Rather, comorbid samples were included, for example patients suffering from depression with and without PTSD, and neural and psychophysiological markers were also investigated. Third, the special issue contains papers ranging from theory-driven experimental lab work to studies conducted in a clinical context. We consider this as a powerful and valuable combination when aiming to make advances for both the clinical and theoretical field.

The special issue starts with the paper by Brown et al. (2018), which provides a comprehensive review of negative appraisals in PTSD. Specifically, the review examines the association between changes in negative appraisals and changes in PTSD symptom severity. Further, mediation of changes in symptoms via negative appraisals is explored. Four studies within the special issue test the role of negative appraisals in a non-clinical and/or lab-based context. Using distressing film clips as an analog trauma induction, Rattel et al. (2018) compare three sampling methods for negative appraisals and intrusions. That is, participants received a prompt to record their intrusions one or five times per day, or recorded their intrusions as they occurred. Further, participants recorded their intrusions retrospectively at the end of the study. Measures of main interest were intrusion frequency and the appraisal of distress related to experiencing intrusions. Woud et al. (2018) test a new approach for measuring negative appraisals. A scenario-based approach was developed in which participants were presented with a set of open-ended scenarios describing ambiguous trauma-relevant events or cognitions. Participants provided their own completions for these scenarios, and the association between participants' spontaneous, idiosyncratic endings and traumarelevant measures was examined. Schweizer et al. (2018) used a real-time, virtual reality analog trauma to induce peri-traumatic stress responses in a sample of healthy individuals. An advantage of this novel trauma analog is that it allows for a first-person experience, which in turn may have the potential to elicit stronger emotional stress responses compared to aversive pictures or film material. Outcomes of main interest were appraisals, emotion regulation strategies, and subjective and physiological responses. Finally, Vermeulen et al. (2018) used a cognitive bias modification (CBM) approach, testing the effects on an appraisal training targeting event centrality in participants with elevated levels of event centrality. Among other measures, the effect of the trainings on posttraumatic stress symptoms such as avoidance and intrusions was assessed.

Moving towards a clinical setting, Rosebrock et al. (2018) examined trauma-related cognitions in a comorbid sample, specifically veterans with unipolar depression, some but not all of whom had a comorbid PTSD diagnosis. Of main interest were cognitive measures assessing rumination and thought suppression. The study by Butler et al. (2018) used functional magnetic resonance imaging (fMRI) during tasks requiring cognitive reappraisal and emotion regulation in a sample of combat-related PTSD patients versus combatexposed controls to investigate the neural underpinnings of these cognitive and emotional strategies. Expanding from previous studies, Sachschal et al. (2018) tested a novel perspective on negative appraisals. That is, they investigated whether individuals suffering from PTSD appraise strangers differently when confronted with both positive and negative information about the unknown person. Similarly, Brake et al. (2018) took a new approach and examined the role of negative appraisals and suicide risk. Here, associations between mental contamination specifically related to posttraumatic mental contamination, symptoms of posttraumatic stress, and cognitions related to suicide risk were tested. Tran and Beck (2018) examined the role of specific peritraumatic factors in the context of trauma-related cognitions and emotions in female patients who had experienced intimate partner violence. Finally, Botsford et al. (2018) applied a qualitative approach investigating stuck-points during treatment. The authors defined stuck-points as negative appraisals identified during the course of psychotherapy, which in turn can affect the therapeutic process negatively. In this study the contents of stuck points, and their relationship with trauma-relevant cognitions, were examined.

The papers collected in this special issue are diverse, provide fresh insights, and pose further questions for future experimental and clinical research on negative appraisals in posttraumatic stress. The special issue is rounded off by a commentary discussing the theoretical, methodological, and clinical issues raised by the reported new findings written 
by Richard McNally and Marcella L. Woud. For now, we would like to invite the reader to enjoy these excellent contributions.

Acknowledgements We thank Lorika Shkreli for her help with preparing the manuscript. Marcella L. Woud is supported by a grant of the Deutsche Forschungsge meinschaft (DFG; WO2018/2-1).

\section{Compliance with Ethical Standards}

Conflict of Interest Marcella L. Woud, Birgit Kleim, and Jan C. Cwik declare that they have no conflict of interest.

Ethical Approval Not applicable.

Informed Consent Not applicable.

Animal Rights Not applicable.

\section{References}

American Psychiatric Association. (2013). Diagnostic and statistical manual of mental disorders: DSM-5 (5. ed.). Washington, DC: American Psychiatric Publishing.

Botsford, J., Steinbrink, M., Rimane, E., Rosner, R., Steil, R., \& Renneberg, B. (2018). Maladaptive post-traumatic cognitions in interpersonally traumatized adolescents with post-traumatic stress disorder: An analysis of "stuck-points". Cognitive Therapy and Research. https://doi.org/10.1007/s10608-018-9928-3.

Brake, C. A., Adams, T. G., Hood, C. O., \& Badour, C. L. (2018). Posttraumatic mental contamination and the interpersonal psychological theory of suicide: Effects via DSM-5 PTSD symptom clusters. Cognitive Therapy and Research. https://doi.org/10.1007/ s10608-018-9959-9.

Brewin, C. R., Dalgleish, T., \& Joseph, S. (1996). A dual representation theory of posttraumatic stress disorder. Psychological Review, 103(4), 670-686. https://doi.org/10.1037/0033-295X.103.4.670.

Brown, L. A., Belli, G. M., Asnaani, A., \& Foa, E. B. (2018). A review of the role of negative cognitions about oneself, others, and the world in the treatment of PTSD. Cognitive Therapy and Research. https://doi.org/10.1007/s10608-018-9938-1.

Bryant, R. A., \& Guthrie, R. M. (2005). Maladaptive appraisals as a risk factor for posttraumatic stress: A study of trainee firefighters. Psychological Science, 16(10), 749-752. https://doi.org/10.111 1/j.1467-9280.2005.01608.x.

Bryant, R. A., \& Guthrie, R. M. (2007). Maladaptive self-appraisals before trauma exposure predict posttraumatic stress disorder. Journal of Consulting and Clinical Psychology, 75(5), 812-815. https://doi.org/10.1037/0022-006X.75.5.812.

Butler, O., Willmund, G., Gleich, T., Zimmermann, P., Lindenberger, U., Gallinat, J., \& Kühn, S. (2018). Cognitive reappraisal and expressive suppression of negative emotion in combat-related posttraumatic stress disorder: A functional MRI study. Cognitive Therapy and Research. https://doi.org/10.1007/s1060 8-018-9905-x.

Dunmore, E., Clark, D. M., \& Ehlers, A. (1999). Cognitive factors involved in the onset and maintenance of posttraumatic stress disorder (PTSD) after physical or sexual assault. Behaviour Research and Therapy, 37(9), 809-829.
Ehlers, A., \& Clark, D. M. (2000). A cognitive model of posttraumatic stress disorder. Behaviour Research and Therapy, 38(4), 319-345. https://doi.org/10.1016/S0005-7967(99)00123-0.

Ehring, T., Ehlers, A., \& Glucksman, E. (2008). Do cognitive models help in predicting the severity of posttraumatic stress disorder, phobia, and depression after motor vehicle accidents? A prospective longitudinal study. Journal of Consulting and Clinical Psychology, 76(2), 219-230. https://doi. org/10.1037/0022-006X.76.2.219.

Foa, E. B., Steketee, G., \& Rothbaum, B. O. (1989). Behavioral/ cognitive conceptualizations of post-traumatic stress disorder. Behavior Therapy, 20(2), 155-176. https://doi.org/10.1016/ S0005-7894(89)80067-X.

Jelinek, L., Wittekind, C. E., Kellner, M., Moritz, S., \& Muhtz, C. (2013). Meta) cognitive beliefs in posttraumatic stress disorder following forced displacement at the end of the second world war in older adults and their offspring. Cognitive Neuropsychiatry, 18(5), 452-462. https://doi.org/10.1080/13546 805.2012.754749.

Kleim, B., Ehlers, A., \& Glucksman, E. (2007). Early predictors of chronic post-traumatic stress disorder in assault survivors. Psychological Medicine, 37(10), 1457-1467. https://doi.org/10.1017/ S0033291707001006.

Kleim, B., Grey, N., Wild, J., Nussbeck, F. W., Stott, R., Hackmann, A.. Ehlers, A. (2013). Cognitive change predicts symptom reduction with cognitive therapy for posttraumatic stress disorder. Journal of Consulting and Clinical Psychology, 81(3), 383-393. https:// doi.org/10.1037/a0031290.

Kraemer, H. C. (1997). Coming to terms with the terms of risk. Archives of General Psychiatry, 54(4), 337. https://doi. org/10.1001/archpsyc.1997.01830160065009.

Ozer, E. J., Best, S. R., Lipsey, T. L., \& Weiss, D. S. (2003). Predictors of posttraumatic stress disorder and symptoms in adults: A meta-analysis. Psychological Bulletin, 129(1), 52-73. https://doi. org/10.1037/0033-2909.129.1.52.

Rattel, J. A., Grünberger, L. M., Reichenberger, J., Liedlgruber, M., Miedl, S. F., Blechert, J., \& Wilhelm, F. H. (2018). Frequency of intrusions and appraisal of related distress after analogue trauma: A comparative ecological momentary assessment methods study. Cognitive Therapy and Research. https://doi.org/10.1007/s1060 8-018-9941-6.

Resick, P. A., \& Schnicke, M. K. (1992). Cognitive processing therapy for sexual assault victims. Journal of Consulting and Clinical Psychology, 60(5), 748-756.

Rosebrock, L. E., Hall, K. A. A., Rando, A., Pineles, S. L., \& Liverant, G. I. (2018). Rumination and its relationship with thought suppression in unipolar depression and comorbid PTSD. Cognitive Therapy and Research. https://doi.org/10.1007/s1060 8-018-9935-4.

Sachschal, S., Woodward, E., \& Ehlers, A. (2018). Appraisal biases about strangers in posttraumatic stress disorder. Cognitive Therapy and Research. https://doi.org/10.1007/s10608-018-9962-1.

Schweizer, T., Renner, F., Sun, D., Becker-Asano, C., \& TuschenCaffier, B. (2018). Cognitive processing and regulation modulates analogue trauma symptoms in a virtual reality paradigm. Cognitive Therapy and Research. https://doi.org/10.1007/s1060 8-018-9967-9.

Ter Heide, F. J. J., Sleijpen, M., \& van der Aa, N. (2017). Posttraumatic world assumptions among treatment-seeking refugees. Transcultural Psychiatry, 54(5-6), 824-839. https://doi.org/10.1177/13634 61517741811.

Tran, H. N., \& Beck, J. G. (2018). Are peritraumatic perceptions of fear/life threat and posttraumatic negative self-conscious appraisals/emotions differentially associated with PTSD symptoms? Cognitive Therapy and Research. https://doi.org/10.1007/s1060 8-018-9903-z. 
Vasterling, J. J., \& Hall, K. A. A. (2018). Neurocognitive and information processing biases in posttraumatic stress disorder. Current Psychiatry Reports, 20(11), 99. https://doi.org/10.1007/s1192 0-018-0964-1.

Vermeulen, M., Brown, A. D., Raes, F., \& Krans, J. (2018). Decreasing event centrality in undergraduates using cognitive bias modification of appraisals. Cognitive Therapy and Research. https://doi. org/10.1007/s10608-018-9936-3.

Woud, M. L., Cwik, J. C., de Kleine, R. A., Blackwell, S. E., Würtz, F., \& Margraf, J. (2018). Assessing trauma-related appraisals by means of a scenario-based approach. Cognitive Therapy and Research. https://doi.org/10.1007/s10608-018-9956-z.

Woud, M. L., Holmes, E. A., Postma, P., Dalgleish, T., \& Mackintosh, B. (2012). Ameliorating intrusive memories of distressing experiences using computerized reappraisal training. Emotion, 12(4), 778-784. https://doi.org/10.1037/a0024992.

Woud, M. L., Postma, P., Holmes, E. A., \& Mackintosh, B. (2013). Reducing analogue trauma symptoms by computerized reappraisal
training-Considering a cognitive prophylaxis? Journal of Behavior Therapy and Experimental Psychiatry, 44(3), 312-315. https ://doi.org/10.1016/j.jbtep.2013.01.003.

Woud, M. L., Verwoerd, J., \& Krans, J. (2017). Modification of cognitive biases related to posttraumatic stress: A systematic review and research agenda. Clinical Psychology Review, 54, 81-95. https:// doi.org/10.1016/j.cpr.2017.04.003.

Woud, M. L., Zlomuzica, A., Cwik, J. C., Margraf, J., Shkreli, L., Blackwell, S. E., Gladwin, T. E., \& Ehring, T. (2018). Effects of appraisal training on responses to a distressing autobiographical event. Journal of Anxiety Disorders, 56, 26-34. https://doi. org/10.1016/j.janxdis.2018.03.010.

Publisher's Note Springer Nature remains neutral with regard to jurisdictional claims in published maps and institutional affiliations. 